\title{
Magnetic nanoparticles enhance the anticancer activity of cathelicidin LL-37 peptide against colon cancer cells
}

\author{
Katarzyna Niemirowicz' \\ Izabela Prokop ${ }^{2}$ \\ Agnieszka Z Wilczewska ${ }^{3}$ \\ Urszula Wnorowska' \\ Ewelina Piktel' \\ Marzena Wątek ${ }^{4}$ \\ Paul B Savage ${ }^{5}$ \\ Robert Bucki ${ }^{1,6}$ \\ 'Department of Microbiological \\ and Nanobiomedical Engineering, \\ Medical University of Bialystok, \\ ${ }^{2}$ Department of Medicinal \\ Chemistry, Medical University of \\ Bialystok, ${ }^{3}$ Institute of Chemistry, \\ University of Bialystok, Bialystok, \\ ${ }^{4}$ Department of Hematology, Holy \\ Cross Oncology Center of Kielce, \\ Kielce, Poland; ${ }^{5}$ Department of \\ Chemistry and Biochemistry, \\ Brigham Young University, Provo, UT, \\ USA; ${ }^{6}$ Department of Physiology, \\ Pathophysiology and Microbiology \\ of Infections, The Faculty of Health \\ Sciences of the Jan Kochanowski \\ University in Kielce, Kielce, Poland
}

Correspondence: Robert Bucki Department of Microbiological and Nanobiomedical Engineering, Medical University of Bialystok, ul. Mickiewicza 2c, I5-222 Bialystok, Poland

$\mathrm{Tel}+48857485483$

Fax +48 857485492

Email buckirobert@gmail.com
This article was published in the following Dove Press journal:

International Journal of Nanomedicine

4 June 2015

Number of times this article has been viewed

\begin{abstract}
The pleiotropic activity of human cathelicidin LL-37 peptide includes an ability to suppress development of colon cancer cells. We hypothesized that the anticancer activity of LL-37 would improve when attached to the surface of magnetic nanoparticles (MNPs). Using colon cancer culture (DLD-1 cells and HT-29 cells), we evaluated the effects of MNPs, LL-37 peptide, its synthetic analog ceragenin CSA-13, and two novel nanosystems, ie, MNP@LL-37 and MNP@CSA-13, on cancer cell viability and apoptosis. Treatment of cancer cells with the LL-37 peptide linked to MNPs (MNP@LL-37) caused a greater decrease in cell viability and a higher rate of apoptosis compared with treatment using free LL-37 peptide. Additionally, we observed a strong ability of ceragenin CSA-13 and MNP@CSA-13 to induce apoptosis of DLD-1 cells. We found that both nanosystems were successfully internalized by HT-29 cells, and cathelicidin LL-37 and ceragenin CSA-13 might play a key role as novel homing molecules. These results indicate that the previously described anticancer activity of LL-37 peptide against colon cancer cells might be significantly improved using a theranostic approach.
\end{abstract}

Keywords: anticancer activity, colorectal cancer, ceragenin, cathelicidin LL-37, magnetic nanoparticles

\section{Introduction}

LL-37 peptide released by serine proteases from its precursor, human cathelicidin, is the only cathelicidin identified so far in humans. ${ }^{1}$ LL-37 has a broad spectrum of antimicrobial activity against a wide range of pathogens, including strains resistant to standard antibiotic therapy. ${ }^{2-4}$ Expression of human cathelicidin/LL-37 significantly increases during tissue regeneration and wound healing and at sites of chronic bacterial infection. ${ }^{5}$ It has been shown that LL-37 binds and neutralizes bacterial cell wall components, such as lipopolysaccharide and lipoteichoic acid, preventing induction of inflammatory mediators via Toll-like receptor activation. ${ }^{2,6}$ A growing number of studies demonstrate the impact of cathelicidin LL-37 in the process of tumor growth. ${ }^{7-9}$ LL-37 is capable of stimulating angiogenesis through an agonistic effect on formyl peptide receptor-like 1 and the prostaglandin E2-EP3 signaling pathway. ${ }^{9,10}$ An increase in apoptosis of tumor cell lines, such as A549 pulmonary epithelial cells, as a result of the agonistic action of LL-37 was reported. ${ }^{11}$ Modified antimicrobial LL-37 peptides, such as FF/CAP18, and a synthetic antimicrobial peptide mimic, ceragenin CSA-13, also have the potential to suppress growth of colon cancer cells. ${ }^{12-15}$ It was found that expression of LL-37 is reduced during progression of stomach cancer from atrophic gastritis to adenocarcinoma. The modified antimicrobial peptide FF/CAP18 exerts antiproliferative effects on the SAS-H1 squamous carcinoma cell line. ${ }^{16}$ The mechanism of action suggested for LL-37 
involves interaction between the cationic domain of LL-37 and negatively charged membrane lipids. ${ }^{17}$ Indeed, electrostatic interactions likely play a key role in attachment of LL-37 and its insertion into tumor cells. ${ }^{17}$ However, several studies have shown that the presence of LL-37 is a positive regulator for progression of certain cancers. In vitro studies revealed that ovarian cancer cells treated with LL-37 are activated to proliferate at a rate similar to that for other mitogens, such as epidermal growth factor. ${ }^{18}$ Similarly, higher proliferation was observed in breast cancer cells overexpressing LL-37. ${ }^{19}$ The mitogenic effects of LL-37 on lung cancer cells and lung cancer xenografts are accompanied by phosphorylation of the epidermal growth factor receptor and subsequent activation of the Ras/mitogen-activated protein kinase cascade. These data suggest that application of the LL-37 peptide might increase the activity of classical chemotherapeutic agents and increase their sensitivity against certain types of cancers. New possibilities to enhance the potential effects of LL-37, its synthetic analog, CSA-13, and other antimicrobial peptides in cancer therapy are provided by strategies that use nanoparticles as a drug delivery system..$^{20,21}$

Studies during the last decade have shown that magnetic nanoparticles (MNPs) have great potential in modern medical applications, including controlled drug and gene delivery systems, magnetic resonance imaging, cancer therapy via magnetic hyperthermia, and targeted therapy. ${ }^{22-25}$ In this study, we describe a novel magnetic nanosystem made from an iron oxide core, aminosilane layer, and the antimicrobial peptide LL-37 or its synthetic analog, CSA-13. Our study provides evidence that combination of antimicrobial peptides with MNPs decreases viability of colorectal cancer cell line. We also show that the ceragenin compound CSA-13 has stronger apoptotic effects on colon cancer cells than LL-37. This study indicates that both nanosystems might play an important role in development of targeted therapy due to their ability to be internalized into cells and accumulate in the nucleus.

\section{Materials and methods}

\section{Synthesis of MNPs functionalized by} cathelicidin LL-37 or its synthetic mimic

Core-shell magnetic nanostructures with terminal propyloamine groups were synthesized by Stober modification methods previously described by Niemirowicz et al. ${ }^{26,27}$ Immobilization of LL-37 peptide onto the nanoparticle surface was achieved by an amidation reaction between the peptide carboxyl group and the primary amine group of the MNPs. To obtain ceragenin-functionalized MNPs, the core-shell nanostructures were suspended in ethanol and a $25 \%$ solution of glutaric dialdehyde. In the final step, MNPs with terminal aldehyde groups were resuspended in ethanol containing ceragenin CSA-13. After functionalization, the precipitate was collected magnetically and washed three times each with ethanol and phosphate-buffered saline, then dried to a powder at $37^{\circ} \mathrm{C}$. To prepare fluorescent nanosystems, MNPs with aldehyde groups were functionalized with propidium iodide. MNPs coated with cathelicidin LL-37 or ceragenin CSA-13 were then labeled with fluorescein isothiocyanate (FITC). ${ }^{28}$

\section{Characterization of nanoparticles}

Fourier transform infrared (FT-IR) spectra were recorded using a Nicolet 6700 FT-IR spectrophotometer (Thermo Scientific, Waltham, MA, USA). A thin layer of sample was placed in direct contact with an infrared attenuated total reflection diamond crystal. All FT-IR spectra were collected in the wavenumber range of $4,000-500 \mathrm{~cm}^{-1}$ by co-adding 32 scans with a resolution of $4 \mathrm{~cm}^{-1}$.

\section{Cell culture}

The two colon cancer cell lines (DLD-1 cells and HT-29 cells) were purchased from American Type Culture Collection (Manassas, VA, USA), and were maintained in Dulbecco's modified Eagle's medium with GlutaMax I (DLD-1) or in McCoy's 5A medium (HT-29), and supplemented with $10 \%$ fetal bovine serum, $50 \mathrm{U} / \mathrm{ml}$ penicillin, and $50 \mathrm{mg} / \mathrm{ml}$ streptomycin at $37^{\circ} \mathrm{C}$ in a $5 \% \mathrm{CO}_{2}$ incubator. Proliferation of DLD-1 cells after treatment with LL-37, CSA-13, MNP, MNP@LL-37, and MNP@CSA-13 was assessed after 24 hours of incubation. The cells were counted using a CKC41 U-RLFT50 microscope (Olympus, Tokyo, Japan). ${ }^{3}$

\section{Evaluation of cytotoxicity using DLD-I and HT-29 cell lines}

To evaluate the cytotoxicity of cathelicidin LL-37, ceragenin CSA-13, MNP@LL-37, and MNP@CSA-13, the cells were seeded at a density of 5,000 cells per well in $1 \mathrm{~mL}$ of growth medium in 24-well plates. After 24 hours of culture, the cells were treated with the test agents at a concentration of 5-100 $\mu \mathrm{g} / \mathrm{mL}$. After 24 hours of incubation, a 3-(4,5-dimethylthiazol-2-yl)-2,5-diphenyltetrazolium bromide (MTT) assay was performed. The average of all the experiments is shown as the cell viability percentage in comparison with the control, while cells without nanoparticles were considered to be $100 \%$ viable.

\section{Apoptosis assay}

Apoptotic cells were analyzed using a vitality kit by determining the level of free thiols, such as reduced glutathione, 
using the NucleoCounter ${ }^{\circledR}$ NC-3000 ${ }^{\mathrm{TM}}$ system, following the manufacturer's instructions. Cells stained with Solution 5 were immediately loaded into an NC-Slide. Solution 5 contains propidium iodide, which stains the dead cells, acridine orange, used as a counterstain staining all cells living and dead, and VB-48 ${ }^{\mathrm{TM}}$ a patented fluorophore which only has fluorescence when bound to reduced thiols. A fluorescence intensity histogram indicating the distribution of thiol levels in cells was collected. The histograms for treated cells and control cells were compared to identify the fraction of cells with low vitality (ie, apoptotic or stressed cells). In another set of experiments apoptotic and necrotic cells were detected using a staining procedure $(5 \mu \mathrm{g} / \mathrm{mL}$ of Hoechst 33342 and $25 \mu \mathrm{g} / \mathrm{mL}$ of propidium iodide, respectively, each in phosphate-buffered saline). Cells were examined for morphological features of apoptosis and necrosis (chromatin condensation, fragmentation, and apoptotic body formation) by confocal microscopy (BD Pathway Bioimaging Systems, BD Biosciences, San Jose, CA, USA) and the images were collected with $400 \times$ magnification.

\section{Proliferation assay}

To examine the effect of cathelicidin LL-37, ceragenin CSA-13, and the synthesized nanoparticles MNP@LL-37 and MNP@CSA-13 on proliferation of HT-29 cells, the cells were seeded in 24 -well plates at $1 \times 10^{5}$ cells/well with $1 \mathrm{~mL}$ of growth medium. After 4 hours, the nanoparticles and $0.5 \mathrm{mCi}$ of $\left[{ }^{3} \mathrm{H}\right]$-thymidine were added to subconfluent cells. Incubation was continued for 24 hours at $37^{\circ} \mathrm{C}$. The cells were then rinsed three times with phosphate-buffered saline and solubilized with $1 \mathrm{~mL}$ of $0.1 \mathrm{~mol} / \mathrm{L}$ sodium hydroxide containing $1 \%$ sodium dodecyl sulfate. Ultima Gold XR scintillation fluid was added, and incorporation of the tracer into DNA was measured in a scintillation counter.

\section{Internalization of functionalized MNPs into HT-29 cells}

Internalization of cathelicidin LL-37, ceragenin CSA-13, and the functionalized nanoparticles MNP@LL-37 and MNP@ CSA-13 was assessed by confocal microscopy, with the images recorded at 400× magnification. HT-29 cells were seeded on 96-well culture plates at a density of $1 \times 10^{5}$ cells/ well with $100 \mu \mathrm{L}$ of growth medium. Next, FITC-labeled cathelicidin LL-37, ceragenin CSA-13 and each nanosystem labeled with propidium iodide and FITC were added at a final concentration of $20 \mu \mathrm{g} / \mathrm{mL}$ and incubated for 8 hours. The cell nuclei were visualized by staining with Hoechst 33342 dye $(5 \mu \mathrm{g} / \mathrm{mL})$ using a confocal microscope equipped with filters (Hoechst/FITC/propidium iodide) and capable of distinguishing between the blue (stained cell nuclei), green (FITC-labeled LL-37 and CSA-13), and red (propidium iodide-labeled MNPs).

\section{Statistical analysis}

In this study, all experiments were carried out in triplicate. Collected data and differences were determined using the one-tailed Student's $t$-test. Statistical analyses were performed using Statistica 10 (StatSoft Inc, Tulsa, OK, USA). $P<0.05$ was considered to be statistically significant.
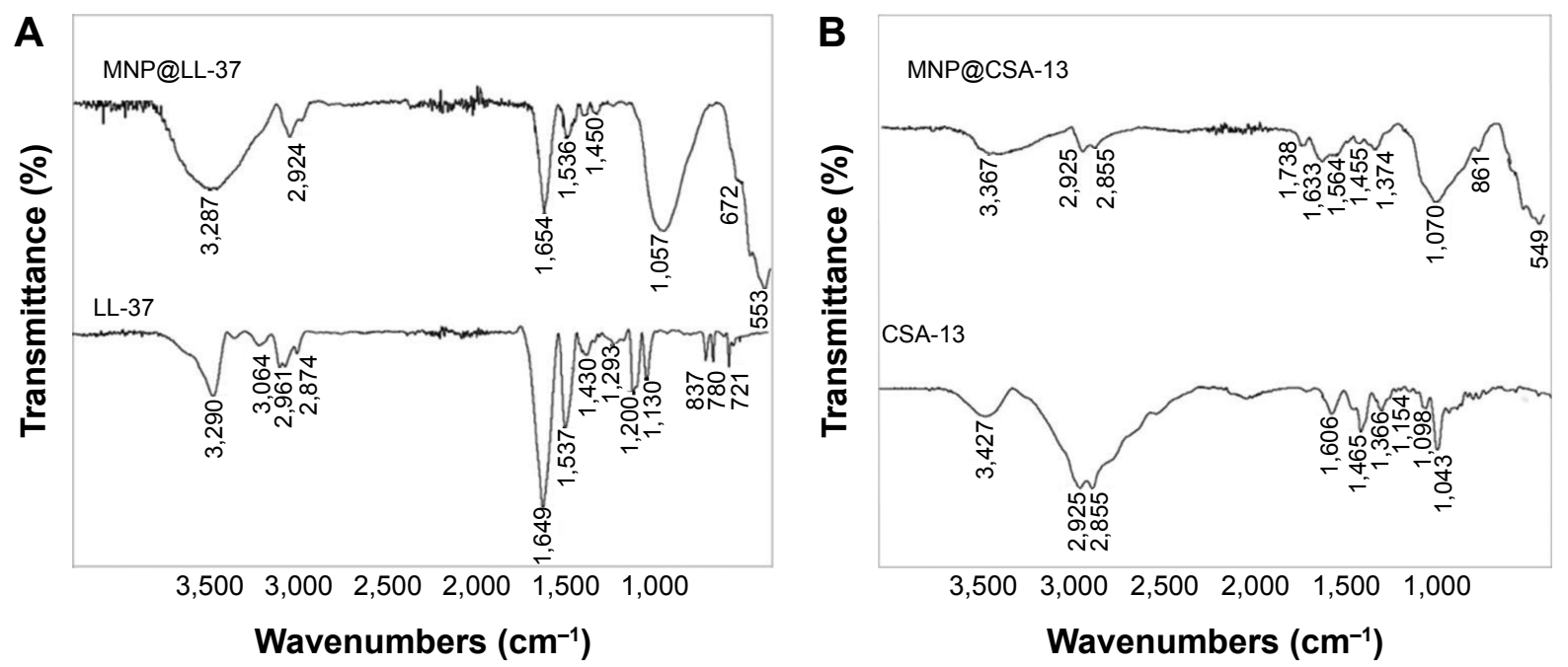

Figure I Attenuated total reflection Fourier transform infrared spectra of magnetic nanoparticles coated by human cathelicidin LL-37 (A) or the antimicrobial peptide analog ceragenin CSA-I3 (B).

Abbreviations: MNP@LL-37, LL-37 peptide linked to magnetic nanoparticles; MNP@CSA-13, CSA-I3 linked to magnetic nanoparticles. 


\section{Results}

\section{Properties of MNP@LL-37 and MNP@ CSA-I 3 nanosystems}

The obtained MNPs were characterized by attenuated total reflection FT-IR spectroscopy. Figure 1 shows the attenuated total reflection FT-IR spectra for LL-37 and MNPs functionalized by cathelicidin LL-37 (MNP@) LL-37, Figure 1A) or ceragenin CSA-13 (MNP@CSA-13, Figure 1B). In each sample, the existence of a magnetic core is indicated by a band at around $550 \mathrm{~cm}^{-1}$, which corresponds to the $\mathrm{Fe}-\mathrm{O}$ stretching mode of $\mathrm{Fe}_{3} \mathrm{O}_{4}$. The presence of an aminosilane layer was confirmed by a distinctive band at around $1,000-1,150 \mathrm{~cm}^{-1}$, which was associated with the $\mathrm{Si}-\mathrm{O}, \mathrm{Si}-\mathrm{O}-\mathrm{Si}$, and Fe-O-Si stretching vibrations. Additionally, the bands at $1,552 \mathrm{~cm}^{-1}$ and $3,367 \mathrm{~cm}^{-1}$ and $3,287 \mathrm{~cm}^{-1}$ correspond to $\mathrm{N}-\mathrm{H}$ bending and stretching vibrations were indicated. After functionalization with cathelicidin LL-37 and ceragenin CSA-13, the characteristic signals for free LL-37 and CSA-13 were recorded within the surfacefunctionalized MNPs, confirming that both molecules were immobilized.

\section{Viability, apoptosis, and proliferation in cell cultures exposed to LL-37, CSA-13, MNPs, MNP@LL-37, and MNP@CSA-I3}

To investigate the effect of cathelicidin LL-37 and its synthetic analog, ceragenin CSA-13 alone and in combination with MNPs, LL-37 and CSA-13 were each covalently immobilized on the surface of MNPs (MNP@LL-37 and MNP@) CSA-13). Each of the above agents was added to the colorectal cancer cells at different concentrations. As shown in Figure 2, LL-37 alone did not significantly affect the survival of DLD-1 cells. In contrast, combination of cathelicidin LL-37 with MNPs caused a dose-dependent cytotoxic response, similar to the effect of CSA-13 and MNP@CSA-13 (Figure 2B). The proliferation assay confirmed the results of the viability studies (Figures 2C and F). A marked dose-dependent decrease in cell proliferation was observed in DLD-1 cells treated with magnetic derivatives of antimicrobial peptides. Similar results were obtained using HT-29 cells (Figures 3C and F). Cationic antimicrobial peptides and their nanoformulations showed concentration-dependent cytotoxicity (Figures 3A and B). Analysis of free thiol levels in cells enabled apoptotic or stressed cells to be identified. As shown in Figures 2D and 3D, LL-37 alone and in combination with MNPs induced apoptosis in about $20 \%$ of DLD-1 cells and less than $10 \%$ of HT-29 cells. However, statistically significant induction of apoptosis was observed when LL-37 was immobilized on the surface of MNPs. After treatment with CSA-13 and MNPCSA-13, there was a statistically significant increase in the amount of apoptotic cells (Figure 3E). However, a CSA-13 dose higher than $20 \mu \mathrm{g} / \mathrm{mL}$ did not have any greater apoptotic effect (Figure 2E). The above observation was confirmed by microscopy. Representative images of HT-29 cells after treatment at a dose of $50 \mu \mathrm{g} / \mathrm{mL}$ are shown in Figure 4.

\section{Cellular internalization of LL-37- and CSA-I3-coated MNPs}

Cellular uptake of free cathelicidin LL-37, ceragenin CSA-13, and the synthesized MNP@LL-37 and MNP@ CSA-13 nanoparticles is demonstrated in Figure 5. The images were used to compare the intracellular localization of all the tested molecules before and after the immobilization process in HT-29 cells. The results show that nanoparticles functionalized by LL-37 or CSA-13 were successfully internalized by HT-29 cells. The data indicate that the nanoparticles accumulated in the cytoplasm while CSA-13 and cathelicidin LL-37 were present in nucleus. Similar localization was indicated for molecules that were not immobilized.

\section{Discussion}

Rapid progress in nanotechnology is now offering considerable opportunities for developing new methods with medical application. Aminosilane-coated MNPs, used as drug carriers, are already well characterized. ${ }^{26}$ In this study, we observed stronger anticancer activity of LL-37 peptide and its synthetic analog, ceragenin CSA-13, after attachment to the surface of MNPs, so nanoparticles could be used to improve the therapeutic activity of such compounds. This possibility is strongly supported by a recent study showing that combination use of MNPs might enhance the activity of conventional chemotherapeutics and reduce their side effects. ${ }^{29,30}$ Additionally, the greater apoptotic effect seen using CSA-13 when compared with natural cathelicidin LL-37 suggests that synthetic cationic mimics of antimicrobial peptides might provide a new therapeutic option. LL-37 peptide and its fragments might be a platform for designing new antitumor drugs, especially for the treatment of cancer cells that are resistant to existing therapeutics. It is suggested that the anticancer mechanism of action of LL-37 is very complex and might involve different pathways. Indirectly, the anticancer effect of LL-37 might be associated with its bactericidal properties, as a relationship between bacterial infections and cancer has been proven, and a reduction of bacterial infections can have a direct impact on the development of cancer. ${ }^{17}$ Further, antimicrobial peptides may kill cancer cells directly in part 

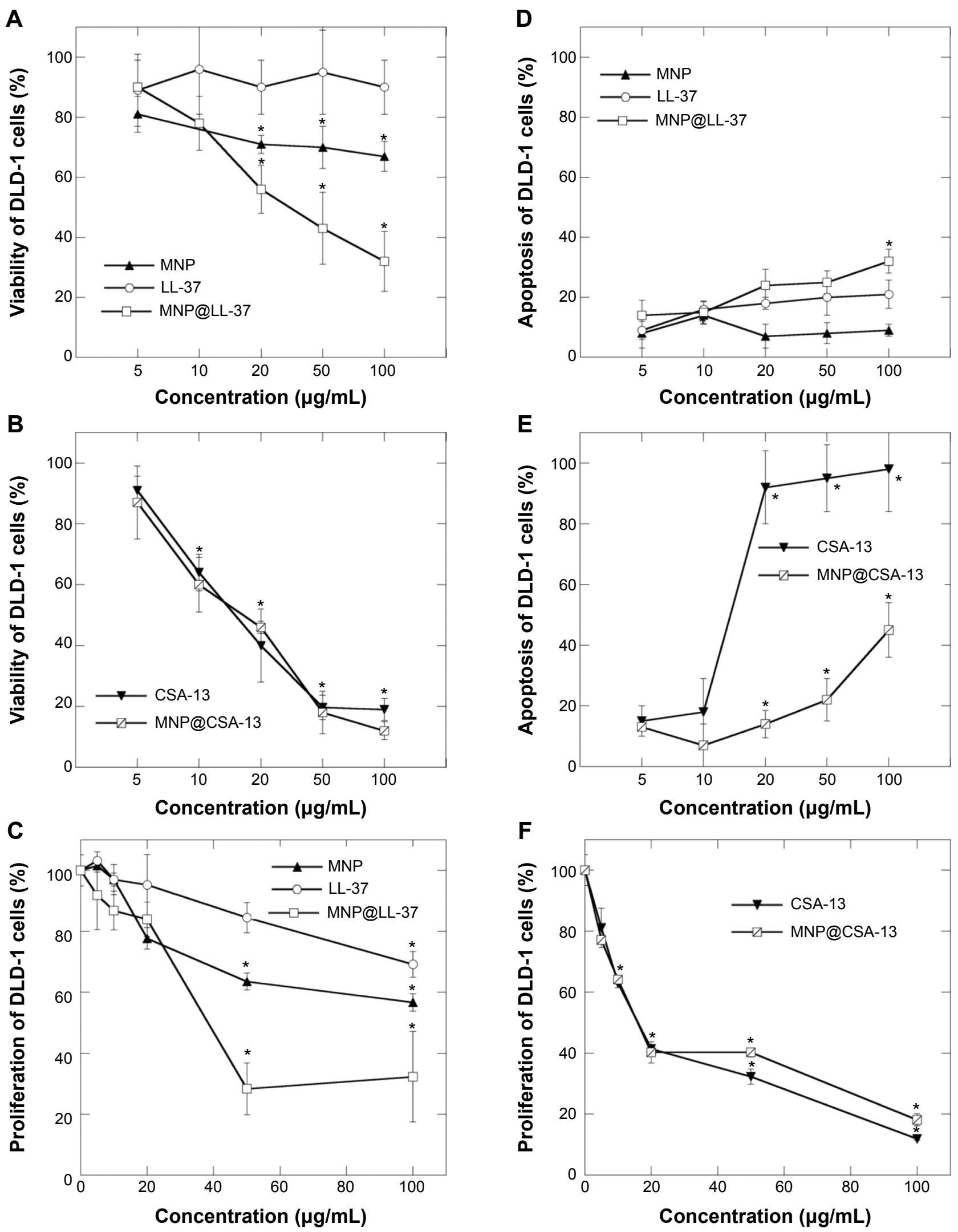

Figure 2 Ceragenin-coated magnetic nanoparticles decrease viability and induce apoptosis in DLD-I cells. MTT assay of the viability of DLD-I cells treated with derivatives of cathelicidin LL-37 (A) and ceragenin CSA-13 (B) at different concentrations for 24 hours. Apoptosis of DLD-I cell treated with cathelicidin LL-37 (D) and ceragenin CSA-13 (E). Proliferation assay of DLD-I cells treated with cathelicidin LL-37 (C) and ceragenin CSA-I3 derivatives (F).

Note: *Significantly different compared with control $(n=3-6)$.

Abbreviations: MNP, Magnetic Nanoparticles; MNP@LL-37, LL-37 peptide linked to magnetic nanoparticles; MNP@CSA-13, CSA-13 linked to magnetic nanoparticles; MTT, 3-(4,5-dimethylthiazol-2-yl)-2,5-diphenyltetrazolium bromide. 
A

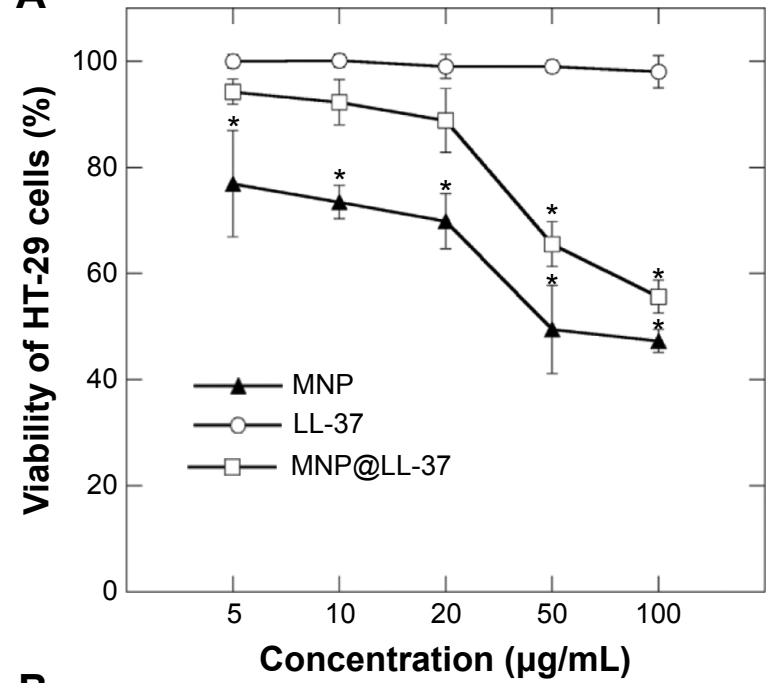

B

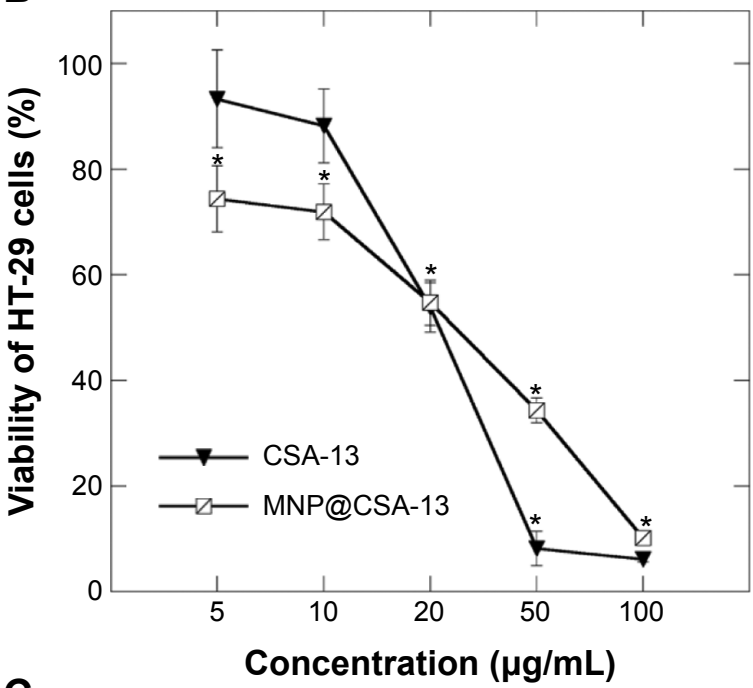

C

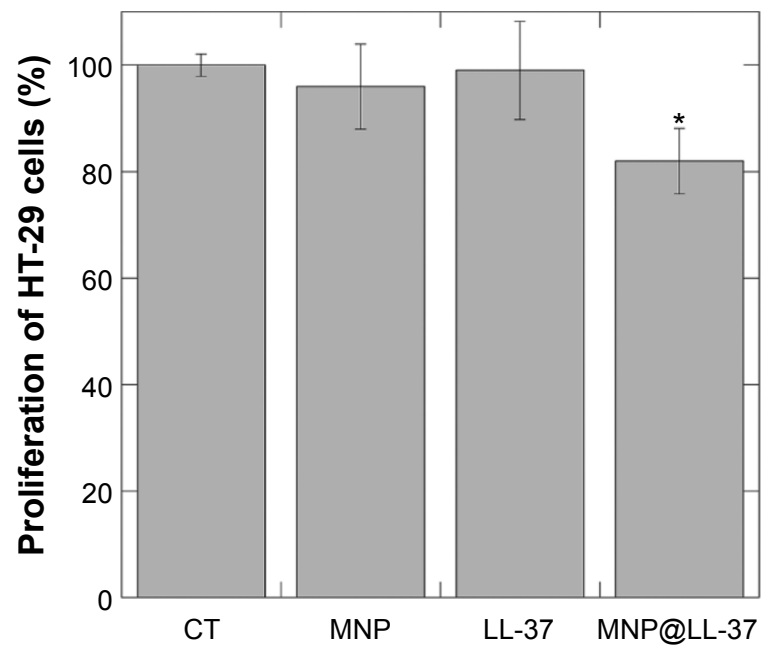

D

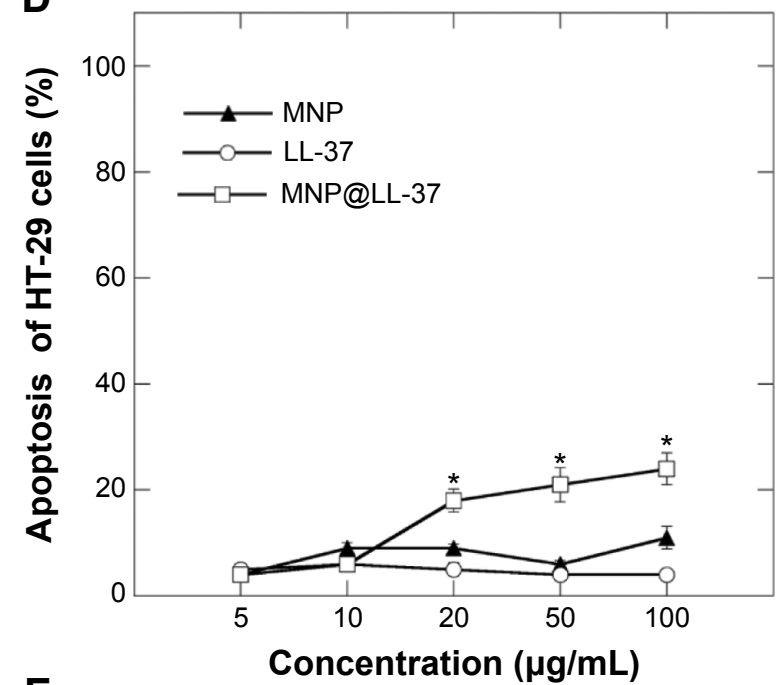

E

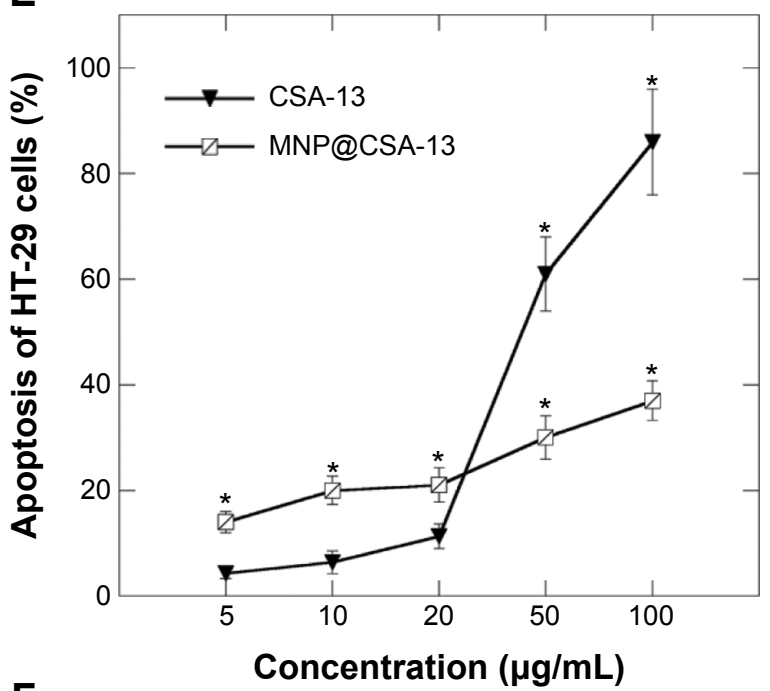

$\mathbf{F}$

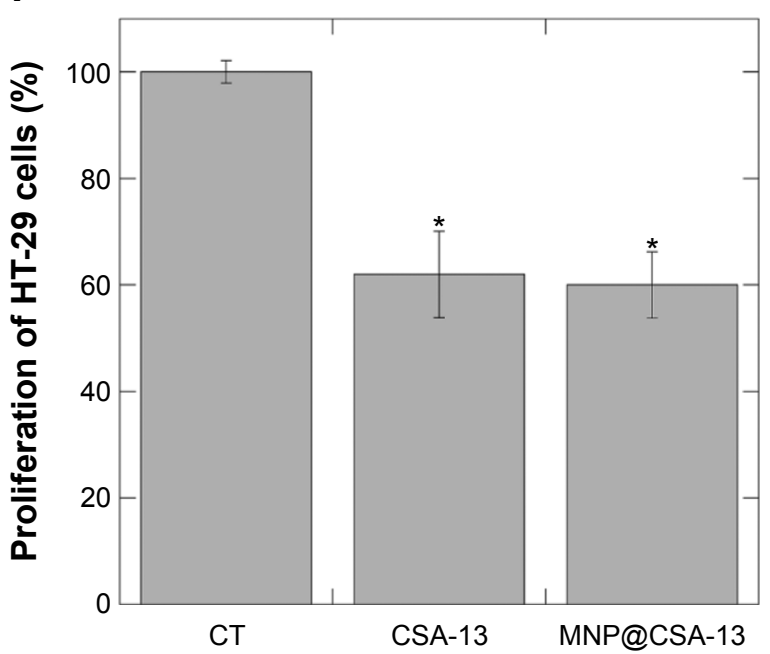

Figure 3 Cathelicidin LL-37-coated and ceragenin CSA-I3-coated magnetic nanoparticles decrease viability, induce apoptosis, and decrease proliferation of HT-29 cells. Viability assay of HT-29 cells treated with derivatives of cathelicidin LL-37 (A) and ceragenin CSA-13 (B) at different concentrations for 24 hours. Apoptosis assay of HT-29 cells after treatment with cathelicidin LL-37 (D) or ceragenin CSA-I3 (E) derivatives. Incorporation of ${ }^{3} \mathrm{H}$-thymidine into HT-29 cells treated with derivatives of cathelicidin LL-37 (C) or ceragenin CSA-I3 (F) for 24 hours at different concentrations.

Note: *Significantly different compared with control $(n=3-6)$.

Abbreviations: MNP, Magnetic Nanoparticles; MNP@LL-37, LL-37 peptide linked to magnetic nanoparticles; MNP@CSA-13, CSA-13 linked to magnetic nanoparticles; CT, control. 

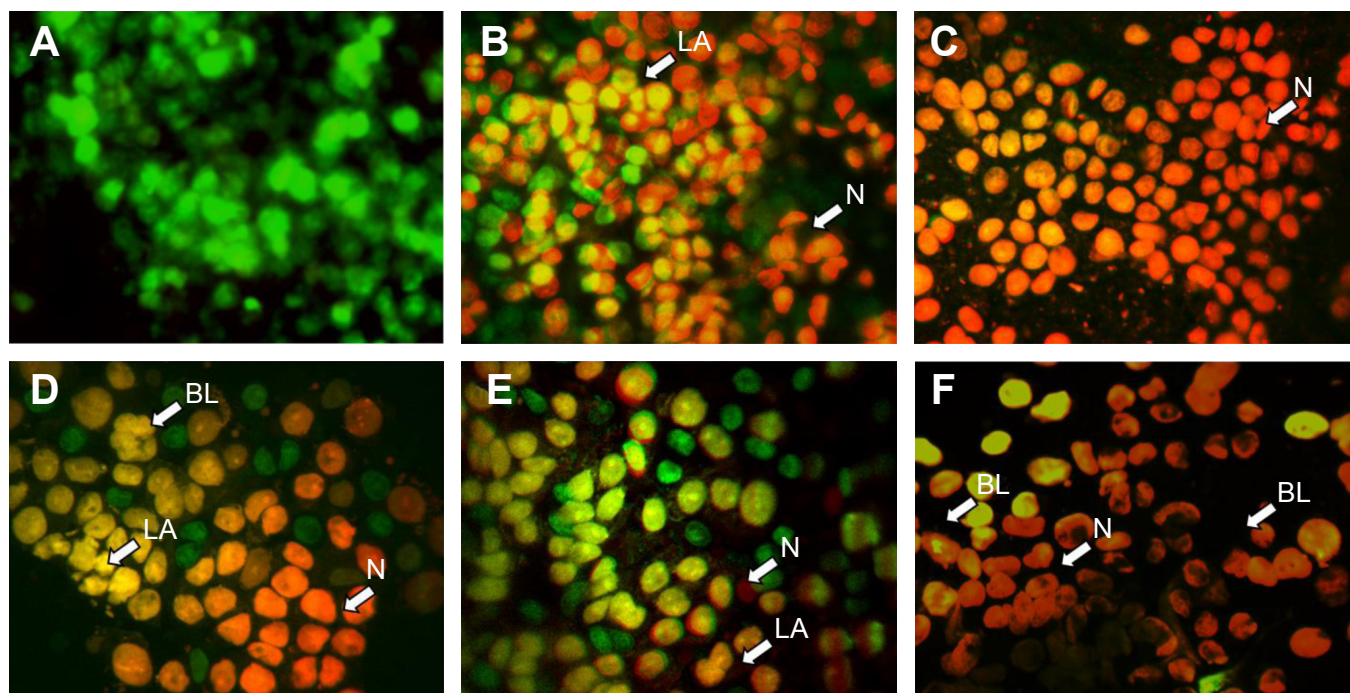

Figure 4 Ceragenin-coated and cathelicidin-coated magnetic nanoparticles induce apoptotic and necrotic changes in HT-29 cells. Microscopy evaluation revealed the normal structure of untreated HT-29 cells without any apoptotic or necrotic changes after 24 hours (A). Apoptotic features, including cell blebbing (BL) were observed after 24 hours of incubation with MNPs (D) or ceragenin CSA-I3 (F). Clear markers of late apoptosis and necrosis were detected by appearance of an orange and red color after treatment with MNP@CSA-I3 (B), MNP@LL-37 (C), MNP (D), and CSA-I3 (F). Uncharacteristic changes were observed after treatment with LL-37 (E).

Notes: The image of the stained HT-29 cell population was acquired using the BD Pathway confocal microscope. Green indicates living cells and orange/red indicates apoptotic or necrotic cells.

Abbreviations: BL, membrane blebbing; LA, late apoptosis; N, necrosis; MNP, magnetic nanoparticles.

due to exposed anionic phosphatidylserines. ${ }^{31}$ A recent study showed that fragments of LL-37, such as FK-16, IG-27, and GF-17, also demonstrated anticancer effects. ${ }^{32}$ LL-37 increases expression of bone morphogenetic protein, which activates tumor-suppressing pathways in gastric carcinogenesis, and inhibits the chymotrypsin-like and caspase-like activity of the $20 \mathrm{~S}$ proteasome. These data suggest that the anticancer effect of LL-37 peptide is mediated via activation of bone morphogenetic protein signaling induced by proteasome inhibition. It might be assumed that the LL-37 peptide complexed with MNPs are able to better activate this pathway. Moreover, it is possible that LL-37 and certain other antimicrobial peptides kill cancer cells indirectly by inducing apoptosis. In a recent and very compelling study, the human cathelicidin/LL-37 analog peptide, FF/CAP18, and CSA-13 exerted antiproliferative effects in an HCT116 (human colon cancer) cell line by depolarization of the mitochondrial membrane, which takes place early in apoptosis. ${ }^{12,13}$ In turn, Zhu et al reported that aminosilane surface coating enhanced cellular uptake efficiency in a number of cell lines. ${ }^{33}$ Kocbek et al showed that breast cancer cells treated with polymer-coated MNPs in the absence of an external magnetic field were observed in membrane compartments. ${ }^{34}$ They also observed that MNPs induced ruffling of the cell surface, which can result from internalization via macropinocytosis. This novel type of endocytosis might be characteristic of solute macromolecules, and probably also of nanoparticles. ${ }^{35}$ This finding is consistent with our results, which show the presence of MNPs in the cytoplasm while active compounds were indicated in their target point (ie, the nucleus). A recent study showed that nanoparticles are able to deliver chemotherapeutic agents to cancer cells with a multidrug resistance mechanism. ${ }^{36}$ Gunduz et al demonstrated that MNPs can escape the activity of the ATP-dependent efflux pump, due to their endocytotic route of internalization, and exert protective effects as well as enhance drug uptake and accumulation. ${ }^{37}$ Other studies have indicated that use of MNPs as a carrier increases the amount of delivered drug. . $^{38,39}$ Some properties of MNPs, such as their high surface area to volume ratio, might partially explain the higher intracellular accumulation of LL-37 in HT-29 cells after treatment with MNP@LL-37, as observed in our study. We hypothesized that MNPs could improve the anticancer properties of antimicrobial peptides because of their improved uptake in colorectal cancer cells (Figure 6). These data alone support our assumption that a synergistic effect of MNPs and cationic antimicrobial peptides might exist. Combining the anticancer activity of LL-37 with the magnetic properties of MNPs may have some prospects for use in vivo magnetic resonance imaging and as an inductor for magnetic hyperthermia. Using the MNPs as LL-37 carriers could be helpful in controlling the balance between the therapeutical and toxic effects of antimicrobial peptides to cancer tissue and surrounding healthy tissue. Factors that could tilt the balance to a diseased state may yield useful methods for the treatment of cancer. 


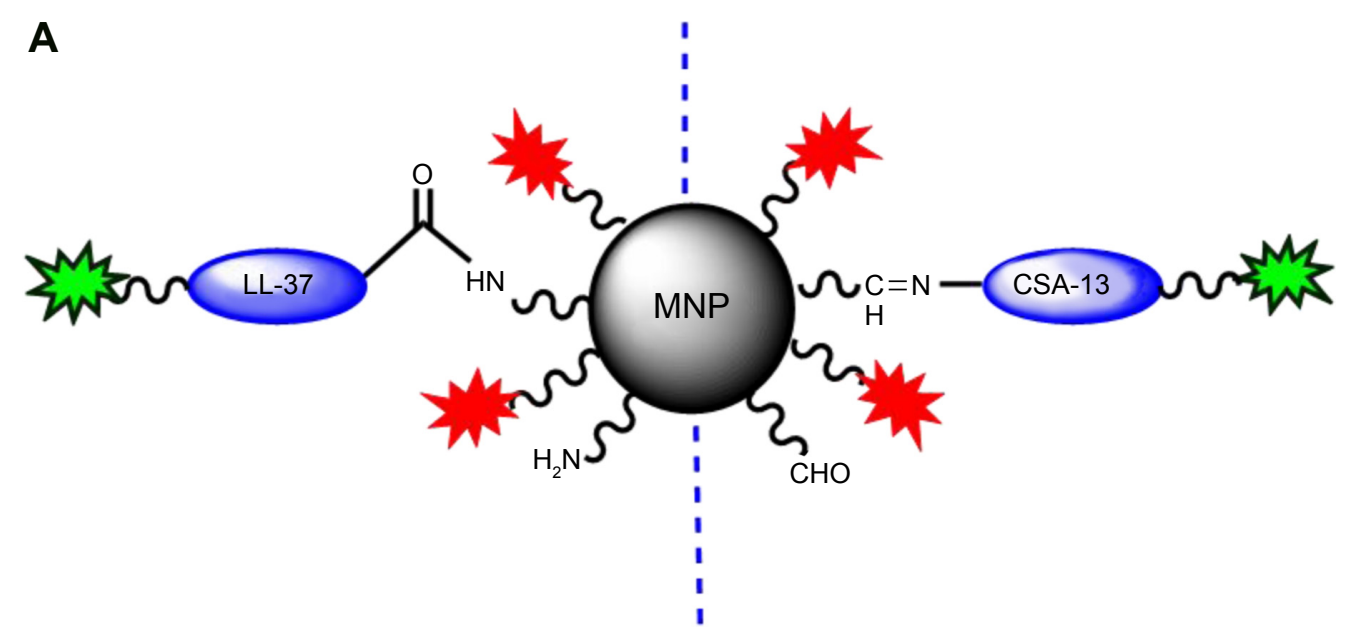

\section{Dual-labeled nanosystem}
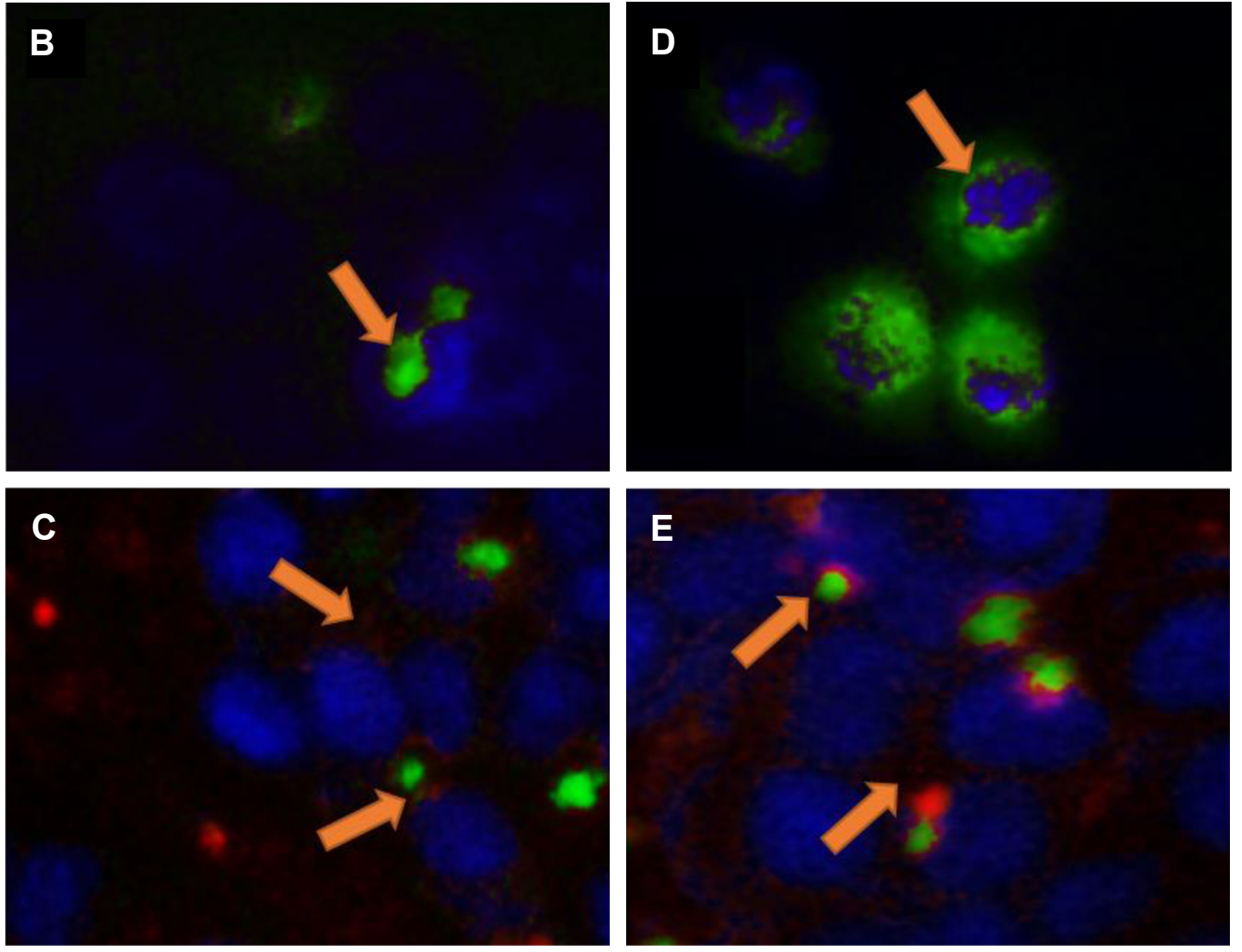

Figure 5 Internalization of the dual-labeled magnetic nanosystem (PI-MNP@LL-37-FITC or PI-MNP@CSA-I3-FITC) into colorectal cancer HT-29 cells. This experiment was conducted using aminosilane-coated MNPs in which cathelicidin LL-37 or ceragenin CSA-I3 attached to the MNP surface were linked to FITC. Additionally, aldehyde groups coating the MNP surface were labeled with PI. Schematic representation of dual-labeled nanosystems (A); FITC is indicated as green stars; PI is indicated as red stars. Internalization of cathelicidin LL-37-FITC (B) or PI-MNP@LL-37-FITC (C), ceragenin CSA-I3-FITC (D) and PI-MNP@CSA-I3-FITC (E). As indicated by arrows, both nanosystems were localized in the cytoplasm and/or nuclear compartment. (C, E) In some cells, LL-37-FITC and CSA-I3-FITC molecules were released from the MNP surface (green fluorescence) and were localized in the nucleus area while the core-shell nanostructures were present in the cytosol (red fluorescence). Magnification 400X. Abbreviations: CSA-I3-FITC, ceragenin CSA-I3 labeled by FITC; LL-37-FITC, cathelicidin LL-37 labeled by FITC; FITC, fluorescein isothiocyanate; PI, propidium iodide; MNP, magnetic nanoparticles; PI-MNP@LL-37-FITC/PI-MNP@CSA-I3-FITC, dual-labeled magnetic nanosystems.

\section{Conclusion}

Aminosilane-modified MNPs can be used as LL-37 carriers when developing tumor-suppressing nanosystems for control of colon and gastric carcinogenesis. This study also indicates that synthetic analogs of LL-37, such as ceragenin CSA-13, represent an improvement on the natural LL-37 peptide for induction of apoptosis in cancer cells. 


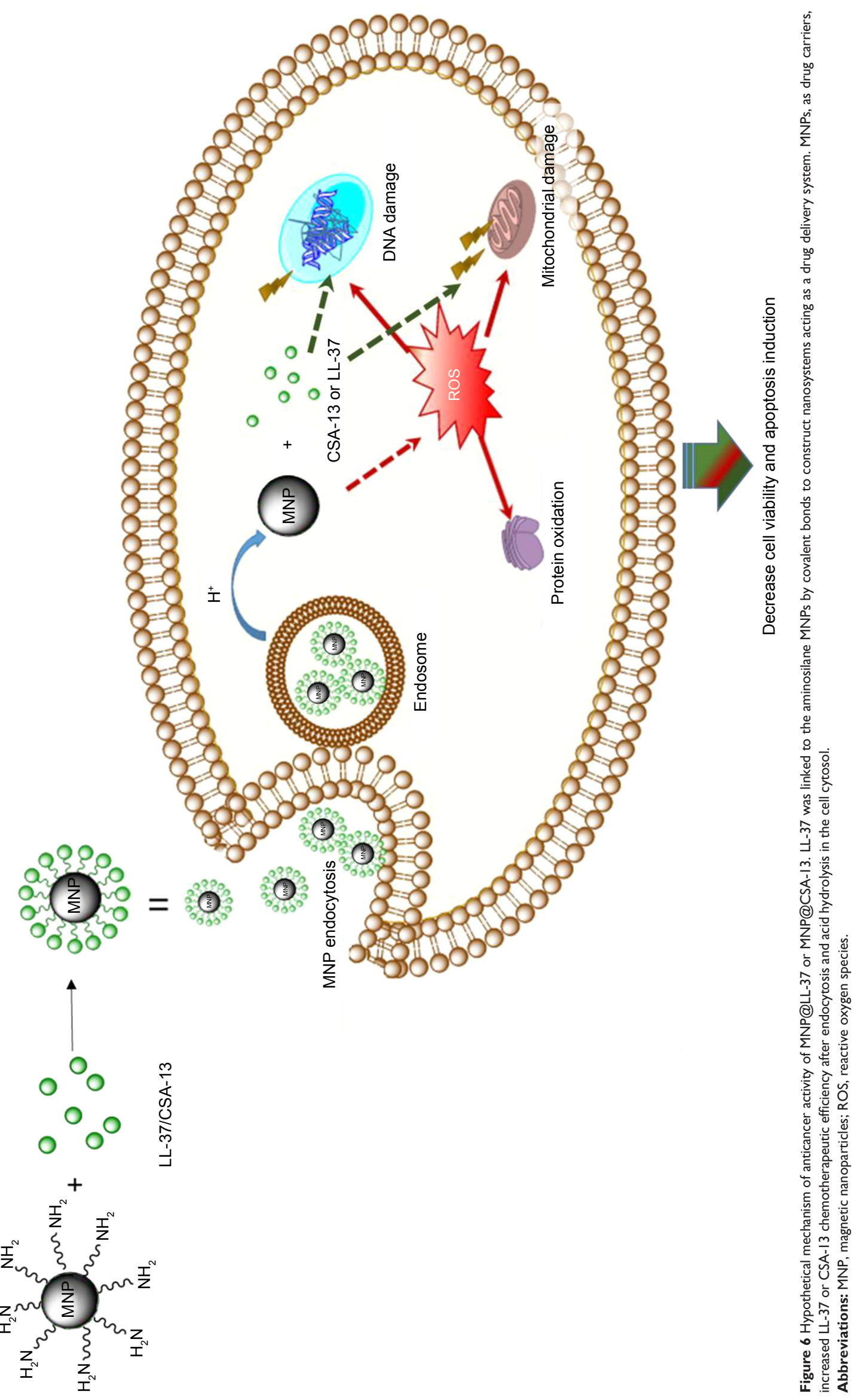




\section{Acknowledgments}

This work was supported by grants from the National Science Centre, Poland (UMO-2012/07/B/NZ6/03504 to RB and UMO-2012/05/N/NZ7/00534 to KN) and the Medical University of Bialystok (144-27928P). IP also acknowledges "Studies, Research, Commercialization - A Support Programme for UMB Doctoral Students" Sub-measure 8.2.1 Human Capital Operational Programme, cofinanced by the European Union under the European Social Fund. The equipment used for analysis of data at the Center of Synthesis and Analysis BioNanoTechno, University of Bialystok, was funded by the European Union, as part of the Operational Program Development of Eastern Poland 2007-2013 (project POPW.01.03.00-20-034/09-00). The authors are grateful to Dariusz Pawlak and Arkadiusz Surażyński for their help in conducting this research.

\section{Disclosure}

The authors report no conflicts of interest in this work.

\section{References}

1. Sørensen OE, Follin P, Johnsen AH, et al. Human cathelicidin, hCAP-18, is processed to the antimicrobial peptide LL-37 by extracellular cleavage with proteinase 3. Blood. 2001;97(12):3951-3959.

2. Bals R, Wilson JM. Cathelicidins - a family of multifunctional antimicrobial peptides. Cell Mol Life Sci. 2003;60(4):711-720.

3. Leszczynska K, Namiot D, Byfield FJ, et al. Antibacterial activity of the human host defence peptide LL-37 and selected synthetic cationic lipids against bacteria associated with oral and upper respiratory tract infections. J Antimicrob Chemother. 2013;68(3):610-618.

4. Bucki R, Leszczyńska K, Namiot A, Sokołowski W. Cathelicidin LL-37: a multitask antimicrobial peptide. Arch Immunol Ther Exp (Warsz). 2010;58(1):15-25.

5. Dorschner RA, Pestonjamasp VK, Tamakuwala S, et al. Cutaneous injury induces the release of cathelicidin anti-microbial peptides active against group A Streptococcus. J Invest Dermatol. 2001;117(1):91-97.

6. Sawa T, Kurahashi K, Ohara M, et al. Evaluation of antimicrobial and lipopolysaccharide-neutralizing effects of a synthetic CAP18 fragment against $P$ seudomonas aeruginosa in a mouse model. Antimicrob Agents Chemother. 1998;42(12):3269-3275.

7. Coffelt SB, Marini FC, Watson K, et al. The pro-inflammatory peptide LL-37 promotes ovarian tumor progression through recruitment of multipotent mesenchymal stromal cells. Proc Natl Acad Sci U S A. 2009; 106(10):3806-3811.

8. Hensel JA, Chanda D, Kumar S, et al. LL-37 as a therapeutic target for late stage prostate cancer. Prostate. 2011;71(6):659-670.

9. Koczulla R, von Degenfeld G, Kupatt C, et al. An angiogenic role for the human peptide antibiotic LL-37/hCAP-18. J Clin Invest. 2003; 111(11):1665-1672.

10. Salvado MD, Di Gennaro A, Lindbom L, Agerberth B, Haeggström JZ. Cathelicidin LL-37 induces angiogenesis via PGE2-EP3 signaling in endothelial cells, in vivo inhibition by aspirin. Arterioscler Thromb Vasc Biol. 2013;33(8):1965-1972.

11. Aarbiou J, Tjabringa GS, Verhoosel RM, et al. Mechanisms of cell death induced by the neutrophil antimicrobial peptides alpha-defensins and LL-37. Inflamm Res. 2006;55(3):119-127.

12. Kuroda K, Fukuda T, Okumura K, et al. Ceragenin CSA-13 induces cell cycle arrest and antiproliferative effects in wild-type and p53 null mutant HCT116 colon cancer cells. Anticancer Drugs. 2013;24(8):826-834.
13. Kuroda K, Fukuda T, Yoneyama H, et al. Anti-proliferative effect of an analogue of the LL-37 peptide in the colon cancer derived cell line HCT116 p53+/+ and p53-/-. Oncol Rep. 2012;28(3): 829-834.

14. Lai XZ, Feng Y, Pollard J, et al. Ceragenins: cholic acid-based mimics of antimicrobial peptides. Acc Chem Res. 2008;41(10):1233-1240.

15. Surel U, Niemirowicz K, Marzec M, Savage PB, Bucki R. Ceragenins a new weapon to fight multidrug resistant bacterial infections. Studia Medyczne. 2014;30(3):207-213.

16. Okumura $\mathrm{K}$, Itoh A, Isogai $\mathrm{E}$, et al. C-terminal domain of human CAP18 antimicrobial peptide induces apoptosis in oral squamous cell carcinoma SAS-H1 cells. Cancer Lett. 2004;212(2):185-194.

17. Wu WK, Wang G, Coffelt SB, et al. Emerging roles of the host defense peptide LL-37 in human cancer and its potential therapeutic applications. Int J Cancer. 2010;127(8):1741-1747.

18. Coffelt SB, Waterman RS, Florez L, et al. Ovarian cancers overexpress the antimicrobial protein hCAP-18 and its derivative LL-37 increases ovarian cancer cell proliferation and invasion. Int J Cancer. 2008;122(5):1030-1039.

19. Heilborn JD, Nilsson MF, Jimenez CI, et al. Antimicrobial protein hCAP18/LL-37 is highly expressed in breast cancer and is a putative growth factor for epithelial cells. Int J Cancer. 2005;114(5):713-719.

20. Huang C, Tang Z, Zhou Y, et al. Magnetic micelles as a potential platform for dual targeted drug delivery in cancer therapy. Int J Pharm. 2012;429(1-2):113-122.

21. Wilczewska AZ, Niemirowicz K, Markiewicz KH, Car H. Nanoparticles as drug delivery systems. Pharmacol Rep. 2012;64(5):1020-1037.

22. Wang X, Liu H, Chen D, et al. MultifunctionalFe3O4@P(St/MAA)@ chitosan@Au core/shell nanoparticles for dual imaging and photothermal therapy. ACS Appl Mater Interfaces. 2013;5(11):4966-4971.

23. Barick KC, Singh S, Bahadur D, Lawande MA, Patkar DP, Hassan PA. Carboxyl decorated Fe3O4 nanoparticles for MRI diagnosis and localized hyperthermia. J Colloid Interface Sci. 2014;418:120-125.

24. Liu Y, Feng L, Liu T, et al. Multifunctional $\mathrm{pH}$-sensitive polymeric nanoparticles for theranostics evaluated experimentally in cancer. Nanoscale. 2014;6(6):3231-3242.

25. Matsushita H, Mizukami S, Sugihara F, Nakanishi Y, Yoshioka Y, Kikuchi K. Multifunctional core-shell silica nanoparticles for highly sensitive (19) f magnetic resonance imaging. Angew Chem Int Ed Engl. 2014;53(4):1008-1011.

26. Niemirowicz K, Swiecicka I, Wilczewska AZ, et al. Gold-functionalized magnetic nanoparticles restrict growth of Pseudomonas aeruginosa. Int J Nanomedicine. 2014;9:2217-2224.

27. Stober, W, Fink, A and Bohn E. Controlled Growth of Monodisperse Silica Spheres in the Micron Size Range. Journal of Colloid and Interface Science. 1968;26:62-69.

28. Choi JH, Kang SR, Kim H, et al. Dye-doped silica nanoparticle with HIV-1 TAT peptide for bioimaging. J Biomed Nanotechnol. 2013; 9(2):291-294.

29. Jalalian SH, Taghdisi SM, Shahidi Hamedani N, et al. Epirubicin loaded super paramagnetic iron oxide nanoparticle-aptamer bioconjugate for combined colon cancer therapy and imaging in vivo. Eur J Pharm Sci. 2013;50(2):191-197.

30. Ruoslahti E, Bhatia SN, Sailor MJ. Targeting of drugs and nanoparticles to tumors. J Cell Biol. 2010;188(6):759-768.

31. Zhou J, Shi J, Hou J, et al. Phosphatidylserine exposure and procoagulant activity in acute promyelocytic leukemia. $J$ Thromb Haemost. 2010;8(4):773-782.

32. Ren SX, Shen J, Cheng AS, et al. FK-16 derived from the anticancer peptide LL-37 induces caspase-independent apoptosis and autophagic cell death in colon cancer cells. PLoS One. 2013;8(5):e63641.

33. Zhu XM, Wang YX, Leung KC, et al. Enhanced cellular uptake of aminosilane-coated superparamagnetic iron oxide nanoparticles in mammalian cell lines. Int J Nanomedicine. 2012;7:953-964.

34. Kocbek P, Kralj S, Kreft ME, Kristl J. Targeting intracellular compartments by magnetic polymeric nanoparticles. Eur J Pharm Sci. 2013; 50(1):130-138. 
35. Lerch S, Dass M, Musyanovych A, Landfester K, Mailänder V. Polymeric nanoparticles of different sizes overcome the cell membrane barrier. Eur J Pharm Biopharm. 2013;84(2):265-274.

36. Ma P, Dong X, Swadley CL, et al. Development of idarubicin and doxorubicin solid lipid nanoparticles to overcome Pgp-mediated multiple drug resistance in leukemia. J Biomed Nanotechnol. 2009;5(2):151-161.

37. Gunduz U, Keskin T, Tansık G, et al. Idarubicin-loaded folic acid conjugated magnetic nanoparticles as a targetable drug delivery system for breast cancer. Biomed Pharmacother. 2014;68(6):729-736.
38. Wang J, Chen B, Chen J, et al. Synthesis and antitumor efficacy of daunorubicin-loaded magnetic nanoparticles. Int J Nanomedicine. 2011; 6:203-211.

39. Wu KC, Yamauchi Y, Hong CY, et al. Biocompatible, surface functionalized mesoporous titania nanoparticles for intracellular imaging and anticancer drug delivery. Chem Commun (Camb). 2011; 47(18):5232-5234.
International Journal of Nanomedicine

\section{Publish your work in this journal}

The International Journal of Nanomedicine is an international, peerreviewed journal focusing on the application of nanotechnology in diagnostics, therapeutics, and drug delivery systems throughout the biomedical field. This journal is indexed on PubMed Central, MedLine, CAS, SciSearch ${ }^{\circledR}$, Current Contents ${ } /$ Clinical Medicine,

\section{Dovepress}

Journal Citation Reports/Science Edition, EMBase, Scopus and the Elsevier Bibliographic databases. The manuscript management system is completely online and includes a very quick and fair peer-review system, which is all easy to use. Visit http://www.dovepress.com/ testimonials.php to read real quotes from published authors.

Submit your manuscript here: http://www.dovepress.com/international-journal-of-nanomedicine-journal 